\title{
PERCEPÇÃO AMBIENTAL DE ESTUDANTES DO ENSINO TÉCNICO FEDERAL EM AGROPECUÁRIA E A CONTRIBUIÇÃO DA EDUCAÇÃO AMBIENTAL NA FORMAÇÃO PROFISSIONAL
}

\author{
Adriana Melo Santos ${ }^{1}$ \\ Elfany Reis do Nascimento Lopes ${ }^{2}$ \\ Milton Ferreira da Silva Junior ${ }^{3}$
}

Resumo: $O$ estudo objetivou analisar a percepção ambiental dos estudantes do ensino técnico em agropecuária do Instituto Federal de Educação, Ciência e Tecnologia Baiano em relação à educação ambiental e a sua importância para a formação profissional. $O$ estudo evidenciou que há um entendimento sobre a dinâmica da interação homem e natureza e os desdobramentos econômicos e sociais deste processo, mas é preciso despertar um olhar sistêmico capaz de evidenciar a inter-relação meio ambiente e setor agropecuário, mitigando os danos ambientais oriundos de tais práticas e estimular a mudança de atitude frente à problemática ambiental.

Palavras-chave: Compreensão Ambiental; Ensino Agrícola; IFBAIANO; Ambiente. 


\section{Introdução}

As discussões em torno dos problemas ambientais têm crescido consideravelmente à medida que o comportamento dos indivíduos frente ao ambiente torna-se o foco na busca de soluções possíveis, tornando evidente o estudo das relações pessoa-ambiente e da necessidade de conservação dos recursos naturais ao longo das atividades cotidianas (LOPES 2013; LOPES; SANTOS, 2014).

Uma possível solução para a crise ambiental está na adequação dos comportamentos humanos por meio de uma relação harmônica destes com o meio ambiente. Como alternativa para melhorar a qualidade de vida do ser humano $e$ as condições ambientais, tem-se a Educação Ambiental, caracterizada por inter-relacionar-se com a postura do ser humano frente ao cotidiano, no qual ele entende como funciona o ambiente, esforça-se para compreender a relação de interdependência entre ambos e desenvolve competências, objetivando promover a sustentabilidade (WALDMAN; SCHNEIDER, 2000; SANTOS et al., 2016).

A educação ambiental é um processo que consiste em propiciar as pessoas uma compreensão crítica e global do ambiente, para elucidar valores e desenvolver atitudes que thes permitam adotar uma posição consciente e participativa a respeito das questões relacionadas com a conservação, a melhoria da qualidade de vida, a eliminação da pobreza extrema e do consumismo desenfreado (MININI, 2000).

Uma gama de autores, dentre eles, Guimarães (1995), Grun (1996), Medina (2001) e Dias (2004) buscaram conceituar a educação ambiental, tendo em vista a evolução do meio ambiente, uma vez que esta deve ser considerada como um processo de interação entre a sociedade e ambiente no qual se vive, através da observação e reflexão sobre ela.

A construção do marco histórico sobre a educação ambiental iniciou quando a palavra foi mencionada pela primeira vez na Conferência em Educação em Keele no ano de 1965, até a Conferência Internacional sobre meio ambiente, no Rio de Janeiro em 1992, estabelecendo orientações de como o processo deveria ocorrer nos espaços formais e informais de educação (DIAS, 2004). A oficialização da educação ambiental no Brasil ocorre em 1981, com a criação da Política Nacional do Meio Ambiente (PNMA), da Política Nacional de Educação Ambiental (PNEA) e da forte influência do cenário internacional (BRASIL, 1981; 1999; SILVA, 2011).

A promulgação da PNEA destaca que todos têm direito à educação ambiental como parte do processo educativo mais amplo e atribui ao poder público, a definição de políticas públicas que incorporem a dimensão ambiental e a promova em todos os níveis de ensino (BRASIL, 2005). Dentro desse aspecto, dar-se-á uma ênfase a educação profissional não por desqualificar a relevância da inserção da temática em outros níveis de ensino, mas por considerar que este nível é o qual os sujeitos desta pesquisa estão inseridos. 
As Referências Curriculares Nacionais da Educação Profissional de Nível Técnico preconizam que a responsabilidade com a preservação do meio ambiente é uma competência a ser construída em todos os cursos desta modalidade, já que os profissionais que vão enfrentar no mundo moderno devem estar preparados para o trabalho e para o exercício da cidadania, sendo um trabalhador pensante e flexível no mundo das tecnologias avançadas (BRASIL, 2000; 2006).

No ensino técnico dos cursos de agropecuária, há em seus debates, o desafio da conjuntura mercadológica oriundo do processo de modernização do setor, caracterizado por Zamberlam e Froncheti (2007) como a transição da agricultura artesanal para a mecanizada. Esse novo cenário requer novas perspectivas formativas, pois de um lado há o promissor setor agrícola, representado pelo avanço do agronegócio, mas do outro encontra-se o processo danoso ao meio ambiente decorrente dessa nova formação profissional (MORAES et al., 200; SOARES, 2001).

Neste sentido, o diálogo e a reflexão sobre a dualidade das frentes de trabalhos para conservação e produção deste profissional devem ser construídos de forma igualitária, tendo auxílio da educação ambiental como pilar de integração e base para o desenvolvimento sustentável. Assim, o processo formativo do técnico em agropecuária deve ter enfoque interdisciplinar, aliando o saber ao fazer educação ambiental, visando contemplar uma abordagem prática, já que o tema meio ambiente está inserido nas discussões da escola somente de maneira teórica (MORAES, 2002).

Este estudo considerou a educação ambiental enquanto vetor de conscientização, respaldando-se em Viezzer (1985) ao afirmar que a educação ambiental deve gerar mudanças na qualidade de vida e maior conscientização da conduta pessoal, além de compreender que este processo perpassa pela percepção ambiental.

Já a percepção foi entendida como o processo cognitivo de apreensão de uma informação ou estímulo presente no ambiente próximo ao individuo, onde uma espécie de estrutura inicial é criada, e a partir dela que as estratégias são criadas para promover soluções às questões relacionadas ao meio ambiente e a reflexão do mundo como espaço de convivência dos seres humanos entre si e deles com a natureza (MARIN, 2003; PATO, 2004; OLIVEIRA, 2005; REIGOTA, 2009; HAMMES, 2012).

Buscou-se neste estudo uma interligação entre a educação ambiental e a educação profissional, buscando conciliar o valor humano necessário à formação de um cidadão e as demandas do mercado de trabalho, reduzindo a visão tecnicista e fortalecendo as relações sociais, a equidade social e sustentabilidade na geração atual e futura (CARVALHO, 2004; GUIMARÃES, 2004; MOREIRA, 2009). Objetivou-se analisar a percepção ambiental dos estudantes do ensino técnico em agropecuária do Instituto Federal de Educação, Ciência e Tecnologia Baiano em relação à educação ambiental e a sua importância para a formação profissional.

Revbea, São Paulo, V. 12, № 2: 136-155, 2017. 


\section{Metodologia}

\section{Área e sujeitos da pesquisa}

O Instituto Federal de Educação, Ciência e Tecnologia Baiano- IF Baiano é uma autarquia consolidada, como Instituição, a partir da integração das Escolas Agrotécnicas Federais da Bahia e das Escolas Médias de Agropecuária Regional da CEPLAC (Comissão Executiva do Plano da Lavoura Cacaueira), a saber: Catu, Santa Inês, Guanambi, Senhor do Bonfim, Uruçuca, Valença, Itapetinga e Teixeira de Freitas. Além dos campi de Bom Jesus da Lapa e Governador Mangabeira.

O Campus Teixeira de Freitas, lócus desse estudo, centraliza-se numa região composta por vinte e um municípios (Alcobaça, Belmonte, Caravelas, Eunápolis, Guaratinga, Ibirapuã, Apebi, Itagimirim, Itabela, Itamaraju, Itanhém, Jucuruçu, Lajedão, Medeiros Neto, Mucuri, Nova Viçosa, Porto Seguro, Prado, Santa Cruz Cabrália, Teixeira de Freitas Vereda) que formam o Território Extremo Sul da Bahia. Oferece cursos técnicos de Agropecuária, Florestas e Hospedagem nas diversas modalidades integrado (ensino médio junto com a formação técnica) e/ou subsequente (exige-se o ensino médio concluído) (BRASIL, 2008).

A amostra pesquisada foi constituída por estudantes do curso Técnico em Agropecuária, na modalidade Integrada, do IF Baiano, campus Teixeira de Freitas, de ambos os sexos, uma vez que na região de abrangência do IF BAIANO Campus Teixeira de Freitas, há uma significativa área rural cultivada, caracterizada pela diversificação de atividades produtivas. $O$ critério utilizado para definição da amostra teve como base a seleção de $20 \%$ dos estudantes regularmente matriculados no ano letivo de 2014, a partir de sorteio aleatório em turmas do curso integrado de Técnico em Agropecuária (Tabela 1).

Tabela 1: Faixa etária dos estudantes do Curso Técnico em Agropecuária - IF Baiano Campus Teixeira de Freitas - Teixeira de Freitas/BA, $2014(n=50)$.

\begin{tabular}{lccccc}
\hline \multicolumn{6}{c}{} \\
\hline Idade inferior a 16 anos & 6 & 7 & 1 & 6 & 6 \\
Faixa etária entre 16 e 21 anos & 3 & 6 & 6 & 9 & 0 \\
\hline Total & 9 & 13 & 7 & 15 & 6 \\
\hline
\end{tabular}

Fonte: Dados da Pesquisa.

\section{Coleta e análise de dados}

Os dados foram coletados por meio de aplicação de questionário estruturado adaptado de Barbosa (2010). A escolha pela utilização de questionários foi fundamentada nas concepções de Dias (2004) que considerou o questionário como um mecanismo de detecção e diagnóstico da Educação Ambiental, contribuindo para o desenvolvimento de questões específicas quando submetidas a grupos determinados, auxiliando na amostragem de opinião e na definição da extensão de um problema. 
Os dados dos questionários foram tabulados e submetidos à análise descritiva, definida por Gil (2002) como uma técnica de observação, registro e analise do objeto de estudo, buscando descrever as características de determinada população ou fenômeno, a partir da relação entre variáveis. A análise da percepção ambiental foi realizada a partir da construção de categorias de análise, a saber: percepção de meio ambiente, atitudes pessoais relacionadas ao meio ambiente, percepção do ambiente local, percepção do curso e percepção dos problemas ambientais locais.

Conforme dispõe a Resolução ํo196/CNS/MS (BRASIL, 1996) visando garantir a integridade ética da pesquisa que envolve seres humanos, esta pesquisa foi submetida e aprovada pelo Comitê de Ética em Pesquisa da Universidade Estadual de Santa Cruz/UESC sob o número de registro 34483414.0.0000.5526.

\section{Resultados e Discussão}

A percepção ambiental dos estudantes do ensino técnico em agropecuária encontra-se apresentada em categorias, permitindo a visualização da compreensão ambiental em diferentes aspectos.

\section{Categoria I - Compreensão de meio ambiente}

Compreender a dinâmica ecossistêmica na visão dos estudantes perpassa pela identificação da sua percepção sobre a relação homemambiente. Os resultados apresentados na Tabela 2 elucidam as concepções de meio ambiente e como estes percebem a relação humana com o meio ambiente.

Tabela 2: Afirmações sobre a concepção de meio ambiente dos estudantes $(n=50)$. Afirmação 01 - Meio ambiente é tudo aquilo que diz respeito aos animais e planas.

\begin{tabular}{|c|c|c|c|c|c|c|}
\hline \multirow[b]{2}{*}{ Turmas } & \multicolumn{6}{|c|}{ Alternativas } \\
\hline & $A$ & B & C & $\mathrm{D}$ & $E$ & NR \\
\hline $1 \stackrel{\circ}{ } A$ no $A$ e $B$ & 2 & 11 & 4 & 2 & 2 & 1 \\
\hline $2^{\circ}$ Ano $A$ e $B$ & 7 & 3 & 3 & 5 & 4 & 0 \\
\hline $3^{\circ}$ Ano & 2 & 1 & 0 & 0 & 3 & 0 \\
\hline Total $(\Sigma)$ & 11 & 15 & 7 & 7 & 9 & 1 \\
\hline
\end{tabular}


...continuação.

Afirmação 02 - O homem não faz parte do meio ambiente.

\begin{tabular}{|c|c|c|c|c|c|c|}
\hline & \multicolumn{6}{|c|}{ Alternativas } \\
\hline Turmas & A & $\mathrm{B}$ & C & D & $E$ & NR \\
\hline $1^{\circ} \mathrm{Ano} A$ e $B$ & 2 & 0 & 0 & 4 & 16 & 0 \\
\hline $2^{\circ} \mathrm{Ano} A$ e $B$ & 0 & 1 & 1 & 2 & 18 & 0 \\
\hline $3^{\circ}$ Ano & 1 & 0 & 0 & 0 & 5 & 0 \\
\hline Total $(\Sigma)$ & 3 & 1 & 1 & 6 & 39 & 0 \\
\hline \multicolumn{7}{|c|}{ Afirmação 03 - A relação entre homem e natureza faz parte do meio ambiente. } \\
\hline & \multicolumn{6}{|c|}{ Alternativas } \\
\hline Turmas & A & $\mathrm{B}$ & C & $\mathrm{D}$ & $\mathrm{E}$ & NR \\
\hline $1^{\circ} \mathrm{Ano} A$ e $B$ & 16 & 6 & 0 & 0 & 0 & 0 \\
\hline $2^{\circ}$ Ano $A$ e $B$ & 10 & 10 & 1 & 1 & 0 & 0 \\
\hline $3^{\circ}$ Ano & 3 & 1 & 0 & 1 & 0 & 1 \\
\hline Total $(\Sigma)$ & 29 & 17 & 1 & 2 & 0 & 1 \\
\hline
\end{tabular}

Afirmação 04 - Cidades, bairros e casas fazem parte do meio ambiente.

Alternativas

\begin{tabular}{ccccccc}
\hline Turmas & A & B & C & D & E & NR \\
\hline 1 Ano A e B & 8 & 6 & 2 & 1 & 4 & 1 \\
2 Ano A e B & 12 & 7 & 1 & 1 & 1 & 0 \\
3 - Ano & 2 & 2 & 0 & 1 & 0 & 1 \\
Total $(\Sigma)$ & 22 & 15 & 3 & 3 & 5 & 2 \\
\hline
\end{tabular}

Afirmação 20 - Problemas com ruídos e problemas sociais não se relacionam com o meio ambiente.

\begin{tabular}{ccccccc}
\hline & \multicolumn{7}{c}{ Alternativas } \\
\hline Turmas & A & B & C & D & E & NR \\
\hline 1 Ano A e B & 3 & 1 & 5 & 1 & 12 & 0 \\
2 Ano A e B & 3 & 1 & 4 & 3 & 11 & 0 \\
$3^{\circ}$ Ano & 0 & 0 & 1 & 0 & 5 & 0 \\
Total $(\Sigma)$ & 6 & 2 & 10 & 4 & 28 & 0 \\
\hline
\end{tabular}

Fonte: Dados da pesquisa.

Conforme a afirmação 01, 26 estudantes (alternativas $A+B$ ) possuem uma visão mais naturalista de ambiente, considerando a natureza e o sujeito como partes distintas, atrelando o conceito de meio ambiente principalmente à flora e a fauna. Observou-se que nove estudantes afirmaram que a alternativa estava incorreta (alternativa E). Essas observações se assemelham com a de Rodrigues et al. (2012), Garrido e Meirelles (2014) e Bezerra et al. (2014) ao identificar nos estudantes uma percepção mais biótica, com elementos da flora e fauna. Essa é visão é classificada por Reigota (2007) como uma abordagem naturalista do meio ambiente que tem a natureza como intocada. 
Considerando a divisão por turmas/ano, os estudantes do $2^{\circ}$ ano em Agropecuária demonstraram uma visão mais abrangente do conceito de meio ambiente. Acredita-se que este fato esteja atrelado a conclusão da disciplina Agroecologia e Gestão Ambiental em um curto espaço de tempo, abordando uma visão mais holística do meio ambiente. É fundamental que os estudantes pesquisados ampliem sua visão e adotem um olhar holístico, compreendendo-o enquanto um sistema interdependente dos aspectos físicos, biológicos, econômicos, psicológicos, sociais e culturais, deixando de lado a visão ultrapassada, quando apenas os aspectos biológicos e físicos eram contemplados na questão ambiental (WATANABE, 2002; GARRIDO; MEIRELLES, 2014).

Sobre o conceito de meio ambiente, 45 estudantes (alternativas $\mathrm{D}+\mathrm{E}$, afirmação 02) compreendem que o homem faz parte do meio ambiente e para 46 estudantes (alternativas $A+B$ ) a relação do homem com a natureza (afirmação 03) é considerada parte integrante da dinâmica ambiental. Para 37 estudantes as cidades, bairros e casas também fazem parte do meio ambiente (alternativas A+B, afirmação 04). Os estudantes do $3^{\circ}$ ano em Agropecuária, por já estarem concluindo o percurso formativo, evidenciaram uma percepção mais crítica da relação estabelecida com o meio ambiente e os seus reflexos no cotidiano.

Há uma contradição que supera as visões de meio ambiente e a inclusão do homem como parte desse meio. A dualidade encontra-se entre a percepção naturalista dos estudantes e a inclusão do homem como integrante do meio ambiente. Para Hammes (2012) essa dualidade é recorrente em investigações sobre a percepção ambiental de indivíduos e, na maioria das vezes, as análises indicam o reconhecimento da importância do meio ambiente para o homem enquanto ser dependente de fatores ambientais para a manutenção da vida.

Ao serem inquiridos sobre a relação entre problemas sociais e o meio ambiente (afirmação 20), 32 estudantes (alternativas $D+E$ ) vêem uma interdependência entre os mesmos. Nos estudos realizados por Lopes et al. (2011) e Leite et al. (2015), a percepção ambiental de estudantes de escolas agrícolas também constatou a relação entre 0 social e o ambiental, especificando principalmente os problemas socioambientais de ausência de saneamento básico, acúmulo de lixo e doenças. $O$ contexto de relação entre o social e o ambiente também é atrelado à percepção acerca dos problemas globais independe da ocorrência local de um problema ambiental (RODRIGUES et al., 2012).

A análise da qualidade de vida pode ser observada na Tabela 3. 
Tabela 3: Afirmações relacionadas à concepção de qualidade de vida dos estudantes $(n=50)$

\begin{tabular}{|c|c|c|c|c|c|c|}
\hline \multirow[b]{2}{*}{ Turmas } & \multirow[b]{2}{*}{$A$} & \multicolumn{5}{|c|}{ Alternativas } \\
\hline & & $\mathrm{B}$ & $\mathrm{C}$ & $\mathrm{D}$ & $E$ & NR \\
\hline $1^{\circ} \mathrm{Ano} A$ e $B$ & 21 & 1 & 0 & 0 & 0 & 0 \\
\hline $2^{\circ}$ Ano $A$ e B & 22 & 0 & 0 & 0 & 0 & 0 \\
\hline $3^{\circ} \mathrm{Ano}$ & 6 & 0 & 0 & 0 & 0 & 0 \\
\hline Total $(\Sigma)$ & 49 & 1 & 0 & 0 & 0 & 0 \\
\hline \multicolumn{7}{|c|}{$\begin{array}{l}\text { Afirmação } 27 \text { - Pessoas que residem na zona rural possuem melhor qualidade de vida que } \\
\text { habitantes da zona urbana. }\end{array}$} \\
\hline & \multicolumn{6}{|c|}{ Alternativas } \\
\hline Turmas & $A$ & $B$ & $\mathrm{C}$ & D & $E$ & NR \\
\hline $1^{\circ} \mathrm{Ano} A$ e $B$ & 11 & 1 & 1 & 0 & 8 & 1 \\
\hline $2^{\circ} A$ no $A$ e $B$ & 14 & 7 & 0 & 0 & 1 & 0 \\
\hline 3ํ Ano & 3 & 3 & 0 & 0 & 0 & 0 \\
\hline Total $(\Sigma)$ & 28 & 11 & 1 & 0 & 9 & 1 \\
\hline
\end{tabular}

Fonte: Dados da pesquisa.

Todos os estudantes (alternativas A + B, afirmação 26) evidenciaram a interligação desta com um ambiente saudável. Os resultados são consonantes com a relação estabelecida por Dorneles e Andiara (2009), quando abordaram que o comprometimento do equilíbrio natural do meio ambiente é oriundo do aumento descontrolado da população, das mudanças de hábitos do ser humano, do avanço tecnológico e do desordenamento da urbanização.

Essa visão também foi observada na percepção de estudantes de Araras (SP), quando indicaram que um ambiente equilibrado necessita ser ambientalmente limpo, com ausência de desmatamento, contaminação dos recursos hídricos por agrotóxicos e fertilizantes químicos e desaparecimento da fauna local (LOPES et al., 2011).

Para 39 estudantes (alternativas $A+B$, afirmação 27), a zona rural proporciona uma melhor qualidade de vida. Estas colocações corroboram com o que Watabane e Abreu (2010) defendem, pois na zona urbana a convergência dos fatos contemporâneos é reflexo das interrelações das sociedades ao longo dos anos, havendo uma degradação do meio natural que se reverte em perda da qualidade de vida. Em contrapartida, a forte pressão e preconceitos pelos quais o meio rural já passou, constata-se que estudantes oriundos destas áreas, podem apresentar um fraco vínculo com as questões ambientais e com o modo de vida rural, renegando os traços ambientais e a qualidade de vida rural (LOPES et al., 2011).

Ainda assim, o fato de todos os estudantes reconhecerem que a qualidade de vida está interligada ao ambiente saudável não pode ser considerado como reflexo da concepção pedagógica do curso que fazem, pois segundo Witier (1997) foi a partir da expansão do movimento ambientalista que a qualidade de vida foi associada à perspectiva da ecologia humana, alicerçada 
às ideias de desenvolvimento sustentável. Contudo, Rameix (1997) salienta que mensurar a qualidade de vida ainda é algo recente e tem o Índice de Desenvolvimento Humano (IDH) como modelo de instrumento sintetizador dessa complexidade.

A Tabela 4 busca evidenciar as especificidades relativas ao solo, uma vez que este é um dos componentes essenciais à atividade agropecuária.

Tabela 4: Afirmações relacionadas à concepção de fatores bióticos e abióticos dos estudantes $(n=50)$.

\begin{tabular}{|c|c|c|c|c|c|c|}
\hline \multicolumn{7}{|c|}{ Afirmação 08 - 0 solo é somente o espaco de onde surgem as plantas. } \\
\hline \multirow[b]{2}{*}{ Turmas } & \multicolumn{6}{|c|}{ Alternativas } \\
\hline & A & $\mathrm{B}$ & $\mathrm{C}$ & $\mathrm{D}$ & $E$ & NR \\
\hline $1^{\circ} \mathrm{Ano} A$ e $B$ & 2 & 7 & 3 & 4 & 6 & 0 \\
\hline $2^{\circ}$ Ano $A$ e $B$ & 1 & 2 & 6 & 7 & 6 & 0 \\
\hline 3ํAno & 1 & 0 & 0 & 0 & 0 & 5 \\
\hline Total $(\Sigma)$ & 4 & 9 & 9 & 11 & 12 & 5 \\
\hline \multicolumn{7}{|c|}{ Afirmação 10 - As florestas têm função social para as comunidades que lá habitam. } \\
\hline & \multicolumn{6}{|c|}{ Alternativas } \\
\hline Turmas & A & $\mathrm{B}$ & $\mathrm{C}$ & $\mathrm{D}$ & $\mathrm{E}$ & NR \\
\hline 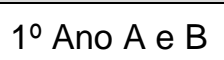 & 8 & 9 & 4 & 0 & 1 & 0 \\
\hline $2^{\circ}$ Ano $A$ e B & 13 & 9 & 0 & 0 & 0 & 0 \\
\hline 3A Ano & 2 & 2 & 0 & 1 & 1 & 0 \\
\hline Total $(\Sigma)$ & 23 & 20 & 4 & 1 & 2 & 0 \\
\hline \multicolumn{7}{|c|}{ Afirmação 09 - O solo é uma região de intensa atividade de microorganismos. } \\
\hline & \multicolumn{6}{|c|}{ Alternativas } \\
\hline Turmas & A & $\mathrm{B}$ & $\mathrm{C}$ & $\mathrm{D}$ & $\mathrm{E}$ & $\mathrm{NR}$ \\
\hline 1ㅇ Ano A e B & 18 & 1 & 2 & 0 & 0 & 1 \\
\hline $2^{\circ}$ Ano $A$ e $B$ & 16 & 6 & 0 & 0 & 0 & 0 \\
\hline 3ํAno & 6 & 0 & 0 & 0 & 0 & 0 \\
\hline Total $(\Sigma)$ & 40 & 7 & 2 & 0 & 0 & 1 \\
\hline
\end{tabular}

Fonte: Dados da pesquisa.

Apenas 13 estudantes (alternativas $A+B$, afirmação 08) consideram que 0 solo é somente o local onde surgem as plantas. $O$ entendimento que fazem parte da estrutura do solo diversos micro-organismos (afirmação 09) é bastante expressivo, uma vez que 47 estudantes (alternativas A + B) concordaram com a afirmação.

Com relação à compreensão da função social das florestas às populações que lá habitam (afirmação 10), 43 estudantes (alternativas A+ B) demonstraram concordar com a afirmativa. É importante observar que os estudantes consideram a floresta fundamental ao equilíbrio natural e determinante para a qualidade do solo.

De acordo com o Censo Agropecuário (IBGE, 2006), no município de 
do solo por meio do cultivo convencional (aração e gradagem), 30 estabelecimentos optam pelo cultivo mínimo (só gradagem) e 42 pelo plantio direto na palha.

O entendimento da dinâmica que envolve o solo e as florestas por parte dos estudantes está em conformidade com o que Marques (2012) alerta. O autor frisou que a retirada da cobertura vegetal natural, pela intervenção do homem acelera os processos erosivos, impactando o setor agrícola, por meio da redução da produtividade da terra e do aumento de custos de produção por causa da necessidade de reposição da fertilidade natural, causando ainda o assoreamento dos rios, lagos e reservatórios d'água, perda da qualidade da água para consumo e a extinção de espécies de peixes e fauna aquática.

Evidenciou-se a necessidade dos estudantes do curso pesquisado ter conhecimento sobre a relevância dos agroecossistemas, bem como da adoção de práticas agrícolas mais sustentáveis, visando melhorar a fertilidade dos solos e evitar a geração de sedimentos oriundos aos processos erosivos.

\section{Categoria II - Atitudes pessoais relacionadas ao meio ambiente}

As intervenções antrópicas são uma das responsáveis pela crise ambiental na contemporaneidade, logo, entender como funcionam as atitudes e comportamentos faz-se fundamental, pois estes impactaram diretamente na conservação do meio ambiente. Para Jaen e Barbudo (2010) as mudanças de atitudes, crenças e valores têm uma relação direta com os comportamentos em relação ao ambiente. Partindo do exposto, a Tabela 5 traz as considerações resultantes das atitudes sobre o comportamento dos sujeitos pesquisados frente ao meio ambiente.

Tabela 5: Afirmações sobre às atitudes pessoais quanto ao ambiente dos estudantes $(n=50)$

\begin{tabular}{|c|c|c|c|c|c|c|}
\hline \multicolumn{7}{|c|}{$\frac{\text { Afirmação } 19 \text { - Minhas atitudes cotidianas não ocasionam danos ao meio ambiente. }}{\text { Alternativas }}$} \\
\hline Turmas & $A$ & $B$ & $\mathrm{C}$ & $\mathrm{D}$ & $E$ & NR \\
\hline $1 \stackrel{\circ}{ } \mathrm{Ano} A$ e $B$ & 3 & 4 & 1 & 3 & 10 & 1 \\
\hline $2^{\circ} A$ no $A$ e $B$ & 2 & 1 & 4 & 5 & 9 & 1 \\
\hline $3^{\circ}$ Ano & 1 & 4 & 0 & 0 & 1 & 0 \\
\hline Total $(\Sigma)$ & 6 & 9 & 5 & 8 & 20 & 2 \\
\hline \multicolumn{7}{|c|}{ Afirmação 18 -Sempre procuro estar informado sobre assuntos ambientais. } \\
\hline & \multicolumn{6}{|c|}{ Alternativas } \\
\hline Turmas & A & B & C & $\mathrm{D}$ & $\mathrm{E}$ & NR \\
\hline $1^{\circ} \mathrm{Ano} A$ e $B$ & 5 & 9 & 1 & 2 & 5 & 0 \\
\hline $2^{\circ}$ Ano $A$ e $B$ & 7 & 9 & 2 & 2 & 2 & 0 \\
\hline $3^{\circ}$ Ano & 2 & 2 & 0 & 1 & 1 & 0 \\
\hline Total $(\Sigma)$ & 14 & 20 & 3 & 5 & 8 & 0 \\
\hline
\end{tabular}


...continuação.

\begin{tabular}{|c|c|c|c|c|c|c|}
\hline \multicolumn{7}{|c|}{ Afirmacão 22 - Penso que ainda preciso me aprofundar mais nos assuntos ligados ao meio } \\
\hline \multicolumn{7}{|c|}{ Alternativas } \\
\hline Turmas & $A$ & $B$ & $\mathrm{C}$ & $D$ & $E$ & NR \\
\hline $1^{\circ} \mathrm{Ano} A$ e $B$ & 19 & 2 & 0 & 0 & 1 & 0 \\
\hline $2^{\circ}$ Ano $A$ e $B$ & 11 & 4 & 2 & 2 & 1 & 1 \\
\hline 3ํ Ano & 3 & 2 & 0 & 1 & 1 & 0 \\
\hline Total $(\Sigma)$ & 33 & 8 & 2 & 3 & 3 & 1 \\
\hline \multicolumn{7}{|c|}{$\begin{array}{l}\text { Afirmação } 21 \text { - Faço separação do lixo de casa para reciclagem (papel, plásticos, metal } \\
\text { orgânico). }\end{array}$} \\
\hline & \multicolumn{6}{|c|}{ Alternativas } \\
\hline Turmas & A & $\mathrm{B}$ & $\mathrm{C}$ & D & $E$ & $\mathrm{NR}$ \\
\hline $1^{\circ} \mathrm{Ano} A$ e $B$ & 2 & 1 & 0 & 1 & 18 & 0 \\
\hline $2^{\circ}$ Ano $A$ e $B$ & 1 & 1 & 2 & 2 & 7 & 9 \\
\hline 3ํ Ano & 1 & 0 & 0 & 0 & 5 & 0 \\
\hline Total $(\Sigma)$ & 4 & 2 & 2 & 3 & 30 & 9 \\
\hline
\end{tabular}

Fonte: Dados da pesquisa.

Inquiridos sobre o reflexo de suas atitudes no meio ambiente, 28 estudantes (alternativas $D+E$, afirmação 19) manifestaram ciência de que os seus atos cotidianos afetam diretamente o meio ambiente. Ainda sobre esse questionamento, 15 estudantes (alternativas $A+B$ ) pensam justamente 0 contrário e a maioria desses encontram-se no $3^{0}$ ano. Diante dos posicionamentos anteriores, os estudantes conseguem perceber a influência do homem sobre o ambiente, mas não conseguem refletir sobre suas atitudes, requerendo a adequação de conceitos e percepção de si enquanto integrante do meio ambiente.

Ao analisar a afirmação 21, em que apenas 6 estudantes (alternativas A + B) alegam que fazem separação do seu lixo doméstico para reciclagem, fica explicita a ausência de uma consciência sobre tal prática. Apesar dos sujeitos pesquisados apontarem uma postura não tão favorável ao meio ambiente, mostraram-se preocupados em obter informações sobre a problemática (afirmação 18). Já 41 estudantes (alternativas $A+B$ ) sinalizaram a intenção de aprofundar seus conhecimentos sobre o tema (afirmação 22).

Para Rodrigues et al. (2012) e Leite et al. (2015), as questões investigadas sobre a atitude ambiental dos estudantes encontram-se fortemente atrelada por uma representação social, construída a partir da tomada de conhecimento destes problemas através da mídia. Para os autores, as informações já vêm carregadas de julgamentos de valor, de posicionamentos ideológicos e de conhecimento científico que são apropriados pelos veículos de comunicação, professores ou agentes sociais e incidem sobre a vida dos estudantes. 


\section{Categoria III - Percepção do currículo do curso quanto à educação ambiental}

Ao refletir sobre o currículo e o seu papel em uma educação orientada à sustentabilidade, deve-se incorporar e apropriar os conteúdos formativos que favoreçam as experiências de aprendizagem pautadas em conhecimentos, habilidades, valores e bens do legado cultural da sociedade. Além disso, devese buscar apoio nos eixos estruturantes da educação contemporânea, cujas diretrizes gerais visam capacitar o aprendiz para a realização nos domínios da ação humana: a vida em sociedade, a atividade produtiva e a experiência subjetiva (TORALES, 2013).

A Tabela 6 demonstra como os estudantes pesquisados visualizam 0 currículo do curso em que estão inseridos, além de pontuar se estes se sentem aptos a atuar enquanto multiplicadores da educação ambiental.

Tabela 6: Afirmações sobre a percepção dos estudantes quanto à articulação curso e a educação ambiental $(n=50)$

\begin{tabular}{|c|c|c|c|c|c|c|}
\hline \multicolumn{7}{|c|}{ Afirmação 23 - O curso que faço não tem relação alguma com meio ambiente. } \\
\hline \multirow[b]{2}{*}{ Turmas } & \multicolumn{6}{|c|}{ Alternativas } \\
\hline & A & B & C & $\mathrm{D}$ & $E$ & NR \\
\hline 10 Ano A e B & 4 & 0 & 0 & 4 & 13 & 1 \\
\hline 2 Ano $A$ e $B$ & 0 & 0 & 0 & 0 & 22 & 0 \\
\hline 3A Ano & 0 & 0 & 0 & 0 & 6 & 0 \\
\hline Total $(\Sigma)$ & 4 & 0 & 0 & 4 & 41 & 1 \\
\hline \multicolumn{7}{|c|}{ Afirmação 24 - O curso que faço não tem relação alguma com educação ambiental. } \\
\hline & \multicolumn{6}{|c|}{ Alternativas } \\
\hline Turmas & A & $\mathrm{B}$ & C & $\mathrm{D}$ & $E$ & NR \\
\hline 10 Ano $A$ e B & 1 & 0 & 0 & 0 & 20 & 1 \\
\hline $2^{\circ}$ Ano $A$ e $B$ & 0 & 0 & 0 & 0 & 22 & 0 \\
\hline 3 Ano & 0 & 0 & 0 & 1 & 5 & 0 \\
\hline Total $(\Sigma)$ & 1 & 0 & 0 & 1 & 47 & 1 \\
\hline \multicolumn{7}{|c|}{$\begin{array}{l}\text { Afirmação } 25 \text { - O técnico em agropecuária pode atuar como um educador ambiental em sua } \\
\text { profissão. }\end{array}$} \\
\hline & \multicolumn{6}{|c|}{ Alternativas } \\
\hline Turmas & $A$ & $B$ & C & $\mathrm{D}$ & $E$ & NR \\
\hline $1^{\circ} \mathrm{Ano} A$ e B & 18 & 2 & 1 & 0 & 0 & 0 \\
\hline $2^{\circ}$ Ano $A$ e B & 13 & 8 & 2 & 0 & 0 & 0 \\
\hline $3^{\circ}$ Ano & 6 & 0 & 0 & 0 & 0 & 0 \\
\hline Total $(\Sigma)$ & 37 & 10 & 3 & 0 & 0 & 0 \\
\hline
\end{tabular}

Fonte: Dados da pesquisa

Observou-se que 47 estudantes (alternativas $A+B$ ) consideram que 0 técnico em agropecuária pode atuar enquanto educador ambiental. Segundo Manucci (2012), o educador ambiental é um agente multiplicador do processo de conscientização em sua comunidade, atuando na transformação e melhoria 
de seu ambiente próximo, por processos dialógicos com os diversos setores da sociedade.

É possível afirmar também que existe o reconhecimento por parte de 45 estudantes (alternativas D + E, afirmação 23) de que o curso que fazem, possui relação com o meio ambiente, tendo a percepção da relação com a educação ambiental confirmada (48 estudantes, alternativas D + E, afirmação 24). Ao sujeito pessoal, cabe o livre arbítrio em envolver-se na defesa do meio ambiente, ou seja, sua vida cotidiana pode ou não refletir atitudes ambientalmente corretas, já o sujeito profissional não lhe deve ser facultado esse direito, sua atuação profissional presume uma ação sustentável.

É preciso enfatizar a importância do professor no caminho da formação dos futuros técnicos em agropecuária. Estudos têm apontado que estes profissionais atuam com uma visão naturalista do ambiente e ausência da noção de educação ambiental como uma ação coletiva. Ainda assim, torna-se necessário sensibilizar estes profissionais para a mudança da visão antropocêntrica que demonstraram ter do meio ambiente e que pouco contribuem para a compreensão e melhoria do ambiente (DIAS, 2004; BEZERRA et al., 2008; MENDES; VAZ, 2009).

\section{Categoria IV - Percepção ambiental local}

Conhecer o ambiente no qual está inserido é fundamental para conscientização ambiental. As Tabelas 7 e 8 apresentam a percepção dos entrevistados com relação aos serviços ambientais disponíveis no município de Teixeira de Freitas. Salienta-se a ausência de questionamentos sobre o abastecimento de água e saneamento básico por ter conhecimento que uma parcela significativa das residências possui cisternas e a cidade, desde 2011, encontra-se em processo de implantação do sistema de saneamento básico.

Tabela 7: Afirmações relacionadas à percepção dos estudantes sobre o abastecimento de água e eletricidade do município de Texeira de Freitas $(n=50)$

\begin{tabular}{|c|c|c|c|c|c|c|}
\hline \multicolumn{7}{|c|}{ Afirmação 13 - A energia elétrica que abastece minha casa provém de usinas hidrelétricas. } \\
\hline & \multicolumn{6}{|c|}{ Alternativas } \\
\hline Turmas & A & $\mathrm{B}$ & C & $\mathrm{D}$ & $\mathrm{E}$ & NR \\
\hline $1^{\circ} \mathrm{Ano} A$ e $B$ & 13 & 6 & 3 & 0 & 0 & 0 \\
\hline $2^{\circ}$ Ano $A$ e $B$ & 7 & 6 & 5 & 0 & 2 & 0 \\
\hline $3^{\circ}$ Ano & 4 & 1 & 0 & 2 & 1 & 0 \\
\hline Total $(\Sigma)$ & 24 & 13 & 8 & 2 & 3 & 0 \\
\hline \multicolumn{7}{|c|}{$\begin{array}{l}\text { Afirmação } 11 \text { - A energia elétrica que abastece nossa região é de origem da queima de carvãc } \\
\text { ou lenha. }\end{array}$} \\
\hline & \multicolumn{6}{|c|}{ Alternativas } \\
\hline Turmas & $A$ & $B$ & $\mathrm{C}$ & $\mathrm{D}$ & $E$ & NR \\
\hline $1^{\circ} \mathrm{Ano} A$ e $B$ & 3 & 0 & 5 & 3 & 9 & 0 \\
\hline $2^{\circ}$ Ano $A$ e $B$ & 0 & 0 & 7 & 4 & 11 & 2 \\
\hline 3A Ano & 0 & 1 & 0 & 1 & 4 & 0 \\
\hline Total $(\Sigma)$ & 3 & 1 & 12 & 8 & 24 & 2 \\
\hline
\end{tabular}

Fonte: Dados da pesquisa.

Revbea, São Paulo, V. 12, № 2: 136-155, 2017. 
Questionados sobre a origem de fontes de energia elétrica (Tabela 7), 37 estudantes (alternativas $A+B$, afirmação 13) têm noção de que a energia do município provém de usinas hidrelétricas. Além de saberem, (32 estudantes, alternativas $D+E$, afirmação 11 ) afirmaram também que não se origina da queima de carvão ou lenha.

A historicidade do processo de ocupação do espaço geográfico demonstra que 0 impacto das atividades está relacionado às suas necessidades de existência, que absorvem, transformam e produzem resíduos. O consumo de produtos menos industrializados, sem embalagens descartáveis é o cerne dessa relação e impactam diretamente nos custos das resoluções dos problemas ambientais, tendo na sociedade a esperança de tornar-se a solução dos mesmos (HAMMES, 2012).

A Tabela 8 ao abordar questões relacionadas aos resíduos sólidos, 31 estudantes (alternativas $A+B$, afirmação 14) reconheceram que após a coleta dos resíduos sólidos em suas residências a destinação desses é o lixão da cidade, frequentado por pessoas em vulnerabilidade socioeconômica à procura de alimentos e outros materiais (48 estudantes, alternativas $A+B$, afirmação 15).

Segundo informações não oficiais coletadas junto a Associação de Catadores de Teixeira de Freitas, diariamente são coletados em média 85 toneladas de resíduos sólidos urbanos, por meio de caminhões basculantes e compactadores, com destinação ao aterro sanitário da cidade. Ressalta-se que em 2009 foi implantada a coleta seletiva no município, fruto da parceria com a referida associação.

Tabela 8: Afirmações relacionadas à percepção dos estudantes sobre resíduos sólidos $(n=50)$

\begin{tabular}{|c|c|c|c|c|c|c|}
\hline \multicolumn{7}{|c|}{$\begin{array}{l}\text { Afirmação } 15 \text {-Há pessoa } \\
\text { materiais. }\end{array}$} \\
\hline & \multicolumn{6}{|c|}{ Alternativas } \\
\hline Turmas & A & $\mathrm{B}$ & $\mathrm{C}$ & $D$ & $E$ & NR \\
\hline $1^{\circ} \mathrm{Ano} A$ e $B$ & 18 & 3 & 1 & 0 & 0 & 0 \\
\hline $2^{\circ}$ Ano $A$ e $B$ & 17 & 5 & 0 & 0 & 0 & 0 \\
\hline $3^{\circ}$ Ano & 4 & 1 & 0 & 1 & 0 & 0 \\
\hline Total $(\Sigma)$ & 39 & 9 & 1 & 1 & 0 & 0 \\
\hline \multicolumn{7}{|c|}{$\begin{array}{l}\text { Afirmação } 14-\mathrm{O} \text { lixo que sai da minha casa é recolhido pela prefeitura e depois vai para } \\
\text { lixão. }\end{array}$} \\
\hline & \multicolumn{6}{|c|}{ Alternativas } \\
\hline Turmas & A & $\mathrm{B}$ & $\mathrm{C}$ & $\mathrm{D}$ & $\mathrm{E}$ & NR \\
\hline 1ㅇ Ano A e B & 8 & 5 & 5 & 2 & 2 & 0 \\
\hline $2^{\circ}$ Ano $A$ e $B$ & 7 & 10 & 0 & 3 & 2 & 0 \\
\hline $3^{\circ}$ Ano & 1 & 0 & 4 & 1 & 0 & 0 \\
\hline Total $(\Sigma)$ & 16 & 15 & 9 & 6 & 4 & 0 \\
\hline
\end{tabular}

Fonte: Dados da pesquisa. 


\section{Categoria $V$ - Opinião da atuação de setores da sociedade na proteção ambiental}

A Tabela 9 apresenta como os estudantes pesquisados percebem a atuação dos diversos setores e instituições com referência ao meio ambiente.

Tabela 9: Opinião dos estudantes d sobre a atuação de setores junto ao meio ambiente $(n=50)$

Questão 28 - Qual é o principal setor responsável pelos danos causados ao meio ambiente?

\begin{tabular}{|c|c|c|c|c|c|c|}
\hline \multirow[b]{2}{*}{ Turmas } & \multicolumn{6}{|c|}{ Alternativas } \\
\hline & Governo & Indústrias & $\begin{array}{c}\text { Setor } \\
\text { Agrícola }\end{array}$ & Sociedade & $\begin{array}{c}\text { Setor } \\
\text { Comercial }\end{array}$ & NR \\
\hline $1^{\circ} \mathrm{Ano} A$ e $B$ & 0 & 1 & 0 & 20 & 0 & 1 \\
\hline $2^{\circ}$ Ano $A$ e $B$ & 4 & 3 & 3 & 11 & 1 & 0 \\
\hline $3^{\circ}$ Ano & 0 & 0 & 0 & 5 & 0 & 1 \\
\hline Total $(\Sigma)$ & 4 & 4 & 3 & 36 & 1 & 2 \\
\hline \multicolumn{7}{|c|}{ Questão 29 - Qual setor é o menor responsável pelos danos ao meio ambiente? } \\
\hline & \multicolumn{6}{|c|}{ Alternativas } \\
\hline Turmas & Governo & Indústrias & $\begin{array}{c}\text { Setor } \\
\text { Agrícola }\end{array}$ & Sociedade & $\begin{array}{c}\text { Setor } \\
\text { Comercial }\end{array}$ & NR \\
\hline $1 \stackrel{\circ}{ }$ Ano $A$ e $B$ & 12 & 0 & 3 & 1 & 5 & 1 \\
\hline $2^{\circ}$ Ano $A$ e $B$ & 6 & 0 & 11 & 0 & 4 & 1 \\
\hline $3^{\circ}$ Ano & 1 & 0 & 2 & 0 & 2 & 1 \\
\hline Total $(\Sigma)$ & 19 & 0 & 16 & 1 & 11 & 3 \\
\hline \multicolumn{7}{|c|}{ Questão 30 - Qual setor é mais envolvido com a proteção do meio ambiente? } \\
\hline & \multicolumn{6}{|c|}{ Alternativas } \\
\hline Turmas & Governo & Indústrias & $\begin{array}{c}\text { Setor } \\
\text { Agrícola }\end{array}$ & Sociedade & $\begin{array}{c}\text { Setor } \\
\text { Comercial }\end{array}$ & NR \\
\hline $1 \stackrel{\circ}{ }$ Ano $A$ e $B$ & 5 & 0 & 14 & 2 & 0 & 1 \\
\hline $2^{\circ}$ Ano $A$ e $B$ & 8 & 0 & 12 & 1 & 0 & 1 \\
\hline $3^{\circ}$ Ano & 4 & 0 & 1 & 0 & 0 & 1 \\
\hline Total $(\Sigma)$ & 17 & 0 & 27 & 3 & 0 & 3 \\
\hline \multicolumn{7}{|c|}{ Questão 31 - Qual setor é menos envolvido com a proteção ao meio ambiente? } \\
\hline & \multicolumn{6}{|c|}{ Alternativas } \\
\hline Turmas & Governo & Indústrias & $\begin{array}{c}\text { Setor } \\
\text { Agrícola }\end{array}$ & Sociedade & $\begin{array}{c}\text { Setor } \\
\text { Comercial }\end{array}$ & NR \\
\hline $1^{\circ} \mathrm{Ano} A$ e $\mathrm{B}$ & 5 & 11 & 0 & 1 & 3 & 2 \\
\hline $2^{\circ}$ Ano $A$ e $B$ & 1 & 10 & 3 & 0 & 6 & 2 \\
\hline $3^{\circ}$ Ano & 0 & 4 & 1 & 0 & 0 & 1 \\
\hline Total $(\Sigma)$ & 6 & 25 & 4 & 1 & 9 & 5 \\
\hline
\end{tabular}

Fonte: Dados da pesquisa.

revista brasileira

educação ambiental
Os estudantes consideraram a sociedade como a principal causadora dos danos ambientais (36 estudantes, afirmação 28) e o governo como quem menos tem responsabilidade por tais danos (19 estudantes, afirmação 29). 16 estudantes apontaram o setor agrícola como principal responsável dessa Revbea, São Paulo, V. 12, № 2: 136-155, 2017. 
questão. A compreensão da percepção da sociedade sobre os problemas e sobre as ações governamentais no processo de gestão pode aproximar o governo local do que a população entende por sua realidade local, ou ainda indicar lacunas existentes no modelo de gestão ambiental (RODRIGUES et al., 2012).

Os estudantes consideram, ainda, o setor agrícola como o mais envolvido (27 estudantes, afirmação 30 ) e as indústrias como o setor menos envolvido (25 estudantes, afirmação 31 ) com a proteção do meio ambiente. 0 município de Teixeira de Freitas, segundo Censo Agropecuário de 2006 possui 741 empreendimentos agropecuários, abrangendo 88.376 hectares (IBGE, 2006). Vale ressaltar que a composição da produção agropecuária do município é o cultivo técnico de eucalipto, ocupando $8 \%$ da área territorial, representando uma importante fonte de emprego e renda.

É relevante ter a agricultura enquanto tema gerador nos projetos de educação ambiental nas instituições de ensino, oportunizando aos estudantes os conhecimentos sobre uma produção mais sustentável em relação a realidade agrícola local, estimulando nos futuros profissionais o uso de práticas conservacionistas, aproximando-os do meio ambiente e ressignificando a zona rural e o valor do agricultor.

É sugerido que a instituição de ensino lócus desse estudo possa fomentar, cada vez mais, práticas que proporcionem o debate e compreensão da dinâmica do meio ambiente e os reflexos das ações antrópica e, desenvolva propostas como a da Embrapa Meio Ambiente com o projeto denominado Macroeducação. Esse projeto foi definido por Hammes (2012) como um método de educação ambiental com intuito de mitigar os impactos das atividades agropecuárias por meio da mudança na cultura organizacional das empresas, tanto da área urbana, como da zona rural.

Por fim, uma reflexão sobre o entendimento dos estudantes sobre o setor ao qual estão especializando-se e que, historicamente, é apontado como um dos mais nocivos ao meio ambiente. Estudo anterior em que se avaliou a formação destes estudantes comprovou que os mesmos têm adquirido ou mostrando-se abertos a mudança de comportamento frente às questões ambientais, adequando-se à conservação dos recursos naturais e a formação ambiental critica e reflexiva a favor do desenvolvimento sustentável (SANTOS et al., 2016).

Os resultados obtidos sobre a percepção ambiental servem como bússola para orientar o desdobramento de orientações posteriores, uma vez que após o diagnóstico da percepção é que deve ocorrer a promoção de ações voltadas à educação ambiental, pois os indivíduos estarão aptos a compreender as interações entre os aspectos físicos, socioculturais e políticoeconômicos que compõem a relação homem-natureza (CANDIANI et al., 2004). 


\section{Conclusões}

O estudo evidenciou que há um entendimento sobre a dinâmica da interação homem e natureza e os desdobramentos econômicos e sociais deste processo. Logo, o protagonismo profissional em prol ao meio ambiente não ocorre por falta de questões conceituais, mas sim pela ausência da visão de co-responsabilidade pela proteção ao meio ambiente.

A compreensão de meio ambiente dos estudantes pesquisados necessita ser ampliada para despertar um olhar sistêmico capaz de evidenciar a sua inter-relação com o setor agropecuário, visando mitigar os danos ambientais oriundo de tais práticas e estimular a mudança de atitude dos futuros profissionais técnicos em agropecuária.

A percepção do ambiente local deve extrapolar a identificação da atuação dos diversos setores e instituições com referência ao meio ambiente, possibilitando a articulação destes com a instituição de ensino.

\section{Referências}

BARBOSA, LC.A. O técnico agrícola e a educação ambiental: diálogos e reflexões em busca da problematização e superação de situações - limites. 2010. 209f. Dissertação (Mestrado em Ensino de Ciências) - Fundação Universidade Federal de Mato Grosso do Sul, Campo Grande, 2010.

BEZERRA, T.M.O.; FELICIANO, A.L.P.; ALVES, A G.C. Percepção ambiental de alunos e professores do entorno da Estação Ecológica de Caetés - Região Metropolitana do Recife-PE. Biotemas, Florianópolis, v. 21, n. 1, p. 147-160, 2008.

BEZERRA, Y.B.S. Análise da percepção ambiental de estudantes do ensino fundamental II em uma escola do município de Serra Talhada (PE). Revista Brasileira de Educação Ambiental, São Paulo, v. 9, n. 2, p. 472-488, 2014.

BRASIL. Lei n. 6. 938 de 31 de agosto de 1981. Dispõe sobre a Política Nacional de Meio Ambiente, seus fins e mecanismos de formulação e aplicação e dá outras providências. Brasília, DF, 1981.

BRASIL. Lei n. 9795 de 27 de abril de 1999. Dispõe sobre a Política Nacional de Educação Ambiental. Brasília, DF, 1999.

BRASIL. Ministério da Educação (MEC). Parâmetros curriculares nacionais. Terceiro e quatro ciclos. Apresentação dos temas transversais. Brasília: MEC/SEF, 2000.

BRASIL. Ministério da Educação (MEC). A implantação da Educação Ambiental no Brasil. Brasília, MEC, 2005.

BRASIL. Ministério da Educação (MEC). Parâmetros Curriculares Nacionais. Terceiro e Quarto Ciclos. Ciências Naturais. Brasília, MEC/SEF, 2006. 
BRASIL. Lei n. 11.892 de 29 de dezembro de 2008. Institui a Rede Federal de Educação Profissional, Científica e Tecnológica, cria os Institutos Federais de Educação, Ciência e Tecnologia, e dá outras providências. Brasília, DF, 2008.

CANDIANI, G. et al. Educação Ambiental: percepção e práticas sobre Meio Ambiente de estudantes do ensino fundamental e médio. Revista Eletrônica do Mestrado em Educação Ambiental, Rio Grande, v. 12, p. 74-89, 2004.

CARVALHO, J.F.C. A temática ambiental e a educação ambiental: uma articulação necessária na formação do técnico agrícola. Santa Maria, UFSM, 2004.

DIAS, G. F. Educação Ambiental: princípios e práticas. 9. Ed. São Paulo, Gaia, 2004.

DORNELES, A.C.B.; ANDIARA, F. A ocupação e o homem: uma análise biocêntrica e antropocêntrica do meio ambiente. Revista Eletrônica de Ciências Sociais Aplicadas, Garibaldi, v. 1, n. 1, p. 1-17, 2009.

GIL, A.C. Como elaborar projetos de pesquisa. 4 Ed. São Paulo, Atlas, 2002. 200p.

GRUN, M. Ética e educação ambiental: a conexão necessária. Campinas, Papirus, 1996.

GUIMARÃES, M. A dimensão ambiental da educação. Campinas: Papirus, 1995.

GUIMARÃES, M. Educação ambiental crítica. In: LAYRARGUES, P.P. (Org.). Identidades da educação ambiental brasileira. Brasília: Ministério do Meio Ambiente, 2004. p. 25-34.

HAMMES, V.S. Educação Ambiental e Cidadania. Brasília, Embrapa, 2012.

INSTITUTO BRASILEIRO DE GEOGRAFIA E ESTATÍSTICA (IBGE). Anuário do Censo Agropecuário. Brasília: IBGE. 2006.

INSTITUTO BRASILEIRO DE GEOGRAFIA E ESTATÍSTICA (IBGE). Teixeira de Freitas. Disponível em < http://cod.ibge.gov.br/235NE> Acesso em: 28 jun 2015.

JAEN, M.; BARBUDO, P. Evolución de las Percepciones Medioambientales de los Alumnos de Educación Secundaria enun Curso Académico. Revista Eureka sobre Enseñanza y Divulgación de lasCiencias, Puerto Real, p. 247250, 2010.

LEITE, D.C. Percepção ambiental em escolas rurais: subsídios para educação ambiental. Revista Brasileira de Educação Ambiental, São Paulo, v. 10, n. 3, p. 134-146, 2015.

LOPES, P.R. et al. Diagnóstico socioambiental: o meio ambiente percebido por estudantes de uma escola rural de Araras (SP). Pesquisa em Educação Ambiental, São Paulo, v. 6, n. 1, p. 139-155, 2011. 
LOPES, E.R.N. Aspectos ambientais e históricos do Sistema Nacional de Unidades de Conservação: 12 anos de implantação. Nature and Conservation, Aquidabã, v. 6, n. 2, p. 6-17, 2013.

LOPES, E.R.N. Turismo e Unidades de Conservação: uma integração para o ecoturismo. Nature and Conservation, Aquidabã, v. 7, n. 1, p. 48-60, 2014.

MANUCCI, M. Macroeducação. In: HAMMES, V. S. Proposta metodológica de macroeducação. (Org.). São Paulo, EMBRAPA, 2012.

MARIN, A.A. Percepção Ambiental e Imaginário dos moradores do município de Jardim/MS. 2003. 307f. Tese (Doutorado em Ecologia e Recursos Naturais) - Universidade Federal de São Carlos, 2003.

MARQUES, R.N. As paisagens quartzíticas do planalto do alto rio grande: relações entre rocha-relevo-solo-vegetação na serra de carrancas. Caminhos de Geografia, Uberlândia v. 13, n. 41, 2012.

MEDINA, N.M. A formação dos professores em Educação Ambiental. In: BRASIL. Secretaria de Educação Fundamental (SETEC). Panorama da Educação Ambiental no Ensino Fundamental. Brasilia, SETEC/MEC, 2001.

MENDES, R.; VAZ, A. Educação ambiental no ensino formal: narrativas de professores sobre suas experiências e perspectivas. Educação em Revista, Belo Horizonte, v. 25, n.03,| p. 395-411, 2009.

MININNI, N.M. A formação dos professores em educação ambiental. In: BRASIL. Ministério da Educação (MEC). Panorama da Educação Ambiental no Ensin Fundamental. Brasília, MEC, 2000.

MORAES, A.C.R. Meio ambiente e ciências humanas. São Paulo, Hucitec, 2002.

MOREIRA, J.S. A educação ambiental na formação do técnico agrícola. 2009. 99p. Dissertação (Mestrado em Educação) - Universidade Federal da Paraíba, João Pessoa, 2009.

OLIVEIRA, N.R. Maternidade de adolescentes de periferias sociais e urbanas: algumas análises à luz da Psicologia Ambiental. Revista Brasileira de Crescimento e Desenvolvimento Humano, São Paulo, v. 15, n. 1, p. 69-77, 2005.

PATO, C. Comportamento ecológico: relação com valores pessoais e crenças ambientais. 2004. 164f. Tese (Doutorado em Psicologia) - Universidade de Brasília, Brasília, 2004

RAMEIX, S. Justifications et difficultés éthiques du concept de qualité de vie. Revue Prévenir, França, v. 33, p. 89-104, 1997.

REIGOTA, M. Meio ambiente e representação social. 7. ed. São Paulo: Cortez, 2007.

REIGOTA, M. O que é educação ambiental. 2. ed. rev. São Paulo: Brasiliense, 2009. 
RODRIGUES, M.L. A Percepção Ambiental Como Instrumento de Apoio na Gestão e na Formulação de Políticas Públicas Ambientais. Saúde e Sociedade, São Paulo, v. 21, n. 3, p. 96-110, 2012.

SANTOS, A.M.; SILVA JÚNIOR, M.F.; LOPES, E.R.N. Gamificando a educação ambiental: o desafio jogando verde no Instituto Federal Baiano. Revista Brasileira de Educação Ambiental, São Paulo, v. 11, n 1, p. 246-263, 2016.

SILVA, P.S. Ações efetivas de educação ambiental na prática escolar. In: SEABRA, G. (Org.). Educação ambiental no mundo globalizado. Uma ecologia de riscos, desafios e resistência. João Pessoa, Editora Universitária/UFPB, 2011.

SOARES, M.D.O. A formação do técnico agrícola sob a perspectiva do desenvolvimento sustentável. 2011. Dissertação (Mestrado em Engenharia Agrícola) - Universidade de Campinas, 2001.

TORALES, M.A. A inserção da educação ambiental nos currículos escolares e o papel dos professores: da ação escolar a ação educativo-comunitária como compromisso político-ideológico. Revista Eletrônica do Mestrado em Educação Ambiental, Rio Grande, v. 1-17, 2013.

VIEZZER, M.L. Tratado de educação ambiental para sociedades sustentáveis. São Paulo, Gaia, 1985.

WALDMAN, M.; SCHNEIDER, D.M. Guia Ecológico Doméstico. São Paulo, Contexto, 2000.

WATANABE, S. Glossário de Ecologia. 4 Ed. São Paulo, 2002.

WITIER, P.L. La qualité de vie. Revue Prévenir, França, v. 33, 0. 61-62, 1997.

ZAMBERLAN, J.F. Caracterização de águas de reservatórios superficiais para uso em microirrigação. 2007. 88f. Dissertação (Mestrado em Engenharia Agrícola), Santa Maria, 2007. 